\title{
HPV Vaccine Acceptability in Heterosexual, Gay, and Bisexual Men
}

\author{
Paul Gilbert, MSPH ${ }^{1}$, Noel T. Brewer, PhD ${ }^{1,2}$, Paul L. Reiter, PhD ${ }^{1,2}$, Terence W. Ng, BS ${ }^{1}$, \\ and Jennifer S. Smith, PhD, MPH ${ }^{1,2}$ \\ ${ }^{1}$ UNC Gillings School of Global Public Health, Chapel Hill, NC, USA \\ ${ }^{2}$ Lineberger Comprehensive Cancer Center, Chapel Hill, NC, USA
}

\section{Abstract}

We know little about men's beliefs about human papillomavirus (HPV) vaccine and willingness to receive it. In January 2009, the authors recruited 296 heterosexual men and 312 gay and bisexual men from a national panel of U.S. households to complete an online survey about HPV and HPV vaccine. The authors analyzed data using logistic regression, controlling for age, education, number of lifetime sexual partners, and urban residence. More gay and bisexual men than heterosexual men were willing to receive HPV vaccine ( $73 \%$ vs. $37 \%$; adjusted odds ratio $=4.99$; $95 \%$ confidence interval $=3.36,7.49)$. Gay and bisexual men reported greater awareness of HPV vaccine, perceived worry about HPV-related diseases, perceived effectiveness of HPV vaccine, and anticipated regret if they declined vaccination and later developed HPV-related disease compared with heterosexual men (all $p$ s $<.05$ ). The lower acceptability and different beliefs among heterosexual men suggest that novel interventions for this group may be needed.

\section{Keywords}

HPV vaccine; Gardasil; males; gay

\section{Introduction}

\begin{abstract}
Infection with human papillomavirus (HPV) is highly prevalent among sexually active men and women (Dunne \& Markowitz, 2006; Giuliano, Lu, et al., 2008), with two types of HPV $(6,11)$ causing the majority of genital warts and two types $(16,18)$ associated with cervical, oropharyngeal, and anal cancers (Walboomers et al., 1999). Carcinogenic HPV types have also been associated with penile cancers in men and vaginal and vulvar cancers in women (Backes, Kurman, Pimenta, \& Smith, 2009; Frisch et al., 1997; Gillison, 2008; Hoots, Palefsky, Pimenta, \& Smith, 2009).
\end{abstract}

\footnotetext{
(C) The Author(s) 2010

Corresponding Author: Paul Gilbert, Health Cognition and Behavior Lab, Department of Health Behavior and Health Education, UNC Gillings School of Global Public Health, 325 Rosenau Hall, CB 7440, Chapel Hill, NC 27599, USA paul.gilbert@unc.edu. Reprints: http://www.sagepub.com/journalsReprints.nav

The opinions expressed in this article are those of the authors and do not necessarily represent those of Merck \& Co., Inc. Merck played no role in the design, planning, or implementation of the study or analysis and reporting of the findings.

Declaration of Conflicting Interests

The author(s) declared a potential conflict of interest as follows:

Jennifer S. Smith has received research grants, honoraria, and consulting fees during the last 4 years from GlaxoSmithKline and worked collaboratively on a research grant from Merck Corporation.
} 
Since approval of the quadrivalent HPV vaccine (HPV4) for females in 2006 (Markowitz et al., 2007), interest in expanding HPV vaccination coverage to males has steadily increased (Bush, 2008; Gillison, Chaturvedi, \& Lowy, 2008; Giuliano, 2007; Giuliano \& Salmon, 2008). In October 2009, the U.S. Food and Drug Administration approved HPV4 for use in boys and young men aged 9 to 26 years (Singer, 2009). In contrast to the recommendation for females, however, the Advisory Committee on Immunization Practices issued only a "permissive" recommendation, allowing HPV vaccination to prevent genital warts in males but stopping short of recommending its routine use (Anonymous, 2009; Markowitz, 2009).

The few published studies of HPV vaccine acceptability among heterosexual men have found lower acceptance than that reported for women (Ferris et al., 2009; Jones \& Cook, 2008). Heterosexual men have low knowledge of and low willingness to get HPV vaccine (Reiter, Brewer, \& Smith, 2009). In contrast, most gay and bisexual men have heard of HPV and are willing to receive HPV vaccine, a level comparable with adult women and parents (Reiter, Brewer, McRee, Gilbert, \& Smith, 2010). HPV vaccine may be particularly attractive to gay men, who are at higher risk for anal cancer than heterosexual men (Daling et al., 1987; Holly et al., 1989; Palefsky, 2008). Indeed, anecdotal reports of off-label use of HPV vaccine prior to FDA approval of HPV4 for males were largely about gay men (Brody, 2007; Molloy, 2008; Picard, 2007).

To our knowledge, no published study has directly compared HPV vaccination attitudes and intentions of heterosexual and gay or bisexual men. Furthermore, most studies of HPV vaccine acceptability in men have used small convenience samples and few have examined national samples (Liddon, Hood, Wynn, \& Markowitz, 2010). We sought to describe HPV vaccine awareness, knowledge, and attitudes in comparable samples of heterosexual, gay, and bisexual men.

\section{Method}

\section{Participants and Procedures}

The University of North Carolina Institutional Review Board approved the study. In January 2009, we interviewed men from a national panel of U.S. households. A commercial survey company composed the panel using list-assisted random-digit dialing, which provided a probability-based sample of U.S. households with telephones (Baker, Bundorf, Singer, \& Wagner, 2003). The survey company had previously collected self-reported sexual orientation data from panel members using a single question: "Are you yourself gay, lesbian, or bisexual?" with answer options of "yes; no; I would prefer not to answer this question." Oversampling gay and bisexual men, the survey company invited 874 male panel members, ages 18 to 59 years, to participate in the online survey. We reassessed participants' sexual orientation using a single survey item, "Do you think of yourself as: gay or homosexual (attracted to men); bisexual (attracted to men and women); heterosexual (attracted to women); something else; not sure?" Ninety-six percent (581/608) of the participants reported concordant sexual orientation at both assessments. Fifteen men who were sampled as gay or bisexual self-identified in our survey as heterosexual, reported sexual behavior only with women, and were subsequently included in the heterosexual sample. Twelve participants identified their sexual orientation as "something else" or "not sure." We recategorized six as heterosexual and six as gay or bisexual based on concordance between the survey company's sexual orientation variable and participants' self-reported reported sexual behavior.

A total of 228 men (26\%) did not respond to the invitation, and 37 (4\%) declined to participate (Figure 1). Compared with participants, nonparticipants were younger, and greater proportions were non-White, earned less than $\$ 60,000$ per year, and did not have a 
college degree. Participants and nonparticipants did not differ in the proportion of each group living with a spouse or partner. One heterosexual man reported already receiving HPV vaccine and was subsequently excluded from analyses.

Gay and bisexual men $(n=312)$ were older than heterosexual men $(n=296)$, and gay and bisexual men were more likely to have college degrees, report household incomes of at least $\$ 60,000$, and live in an urbanized area than heterosexual men (Table 1). Survey participants were drawn from 47 states and the District of Columbia, with no differences in regions between groups. Gay and bisexual men reported younger age at first intercourse, more lifetime sexual partners, and riskier sexual behavior in the last year than heterosexual men. Fifty-two gay or bisexual men $(17 \%)$ and one heterosexual man $(<1 \%)$ reported being HIV positive.

\section{Measures}

The survey appears online, http://www.unc.edu/ ntbrewer/2009_men.pdf We adapted items from the Carolina HPV Immunization Measurement and Evaluation Project (Fazekas, Brewer, \& Smith, 2008; Keating et al., 2008) and cognitively tested the survey with 28 gay and bisexual men. These individual face-to-face interviews probed respondents' comprehension, judgment, and response processes, with the goal of detecting potential problems in questions before launching the survey (Willis, 2005). We used the cognitive interview results to revise the items and further tested the survey via in-depth interviews with an additional eight gay and heterosexual men.

The survey assessed awareness of HPV by asking respondents if they had heard of human papillomavirus prior to the survey. We assessed knowledge with nine HPV knowledge questions. We assessed perceived knowledge of genital warts, oral cancer, and anal cancer using three items (e.g., "How much would you say you know about [HPV-related disease]?"), accompanied by a response scale that ranged from nothing at all (coded as 1) to quite a lot (coded as 4). We created a summary score for perceived knowledge of HPVrelated diseases by taking the mean of the three disease-specific items. Following the knowledge items, we provided all men with a brief statement about HPV. ("HPV is a common sexually transmitted disease [STD] that can cause genital warts and cervical cancer. HPV also causes anal cancer and may cause oral and penile cancer.") The survey asked men if they had ever heard of HPV vaccine prior to the survey. Among those who reported hearing about HPV prior to the survey, the survey inquired about sources of information and attitudes toward HPV vaccine.

After giving a more detailed description of HPV vaccine ("Researchers recently found that the HPV vaccine protects men from getting most genital warts. Researchers are also studying whether the HPV vaccine protects men against HPV-related cancers. Although the vaccine is not yet approved for men, some doctors are already giving HPV vaccine to men using a legal loop-hole called 'off-label use."'), the survey measured how willing men would be to get it were it approved for use in males, using five survey items, each accompanied by a 5-point response scale that ranged from definitely not willing to definitely willing $(\alpha=.97)$. We created a summary willingness variable, classifying men who reported probably willing or definitely willing on at least three of the five items as willing to receive HPV vaccine. We chose a dichotomous willingness variable to describe acceptability in a compact way that would yield percentages with a clear interpretation. The survey measured perceived likelihood of developing HPV-related disease (genital warts, anal cancer, oral cancer, penile cancer) without vaccination using items accompanied by 5-point response scales (no chance coded as 1 to certain I will get disease coded as 5). We averaged the variables to create a scale (four items, $\alpha=.89$ ). Similarly, the survey measured perceived effectiveness of HPV vaccine against the same diseases (no protection coded as 1 to 
complete protection coded as 5), which we averaged to create a scale (four items, $\alpha=.92$ ). The survey measured perception of possible barriers to receipt of HPV vaccine: short-term pain or discomfort, long-term adverse effects, cost of the vaccine, and difficulty finding a health care provider who would provide HPV vaccine to males (not at all coded as 1 to extremely coded as 5). We averaged the items to create a scale (four items, $\alpha=.68$ ). The survey measured anticipated regret if they developed an HPV-related disease (genital warts, HPV infection that could lead to cancer) because they did not receive HPV vaccine (not at all coded as 1 to quite a lot coded as 4 ), averaged to create a scale (two items, $\alpha=0.85$ ).

We asked participants about vaccine-related behaviors, including whether they had ever received any doses of HPV vaccine, attempted to get HPV vaccine but were unsuccessful, talked to a doctor about getting HPV vaccine for themselves, whether any family members or friends had received HPV vaccine, where they would find information about HPV vaccine for males, and whether participants believed their health care provider would recommend they get the vaccine if it were approved for males.

We asked participants about sexual behaviors relevant to HPV infection, including age at first intercourse, total number of lifetime sexual partners, previous diagnoses of sexually transmitted infections, and number and type of sexual partners in the last year. Participants reported total number of lifetime sexual partners as a continuous variable. Because these data were positively skewed, we created a four-level categorical variable ( $\leq 4$ partners, 5-19 partners, $20-49$ partners, $\geq 50$ partners). We created a categorical variable to describe sexual risk in the past year: none (zero sexual partners), low risk (one mutually monogamous regular sexual partner), and high risk (two or more sexual partners or a nonmonogamous regular sexual partner). Because of the item-missing data, however, we were unable to compute values for sexual risk in the past year for 11 heterosexual men and 12 gay or bisexual men.

\section{Statistical Analyses}

To maximize statistical power, we placed men who identified as gay or bisexual into a single category for comparisons with heterosexual men. In preliminary analyses, we identified differences between heterosexual men and gay and bisexual men on demographic variables to control for in later analyses. In our main analyses, we used bivariate logistic regression to examine differences in dichotomous outcomes (knowledge, attitudes, and intention), reporting odds ratios (ORs) and 95\% confidence intervals (95\% CIs). We used bivariate linear regression to examine continuous outcomes (beliefs and attitudes), reporting standardized beta coefficients $(\beta)$. We repeated these analyses using multivariate regressions that controlled for age, educational attainment, household income, any previous STI diagnosis, number of lifetime sex partners, and urbanicity. We did not control for age at first intercourse to avoid multicollinearity with other control variables, and we did not control for sexual risk because of missing data. We analyzed data using SPSS 17.0 (Chicago, IL). All statistical tests were two-tailed, using a critical $\alpha$ of .05 .

\section{Results \\ HPV and HPV-Related Diseases}

More gay and bisexual men reported hearing about HPV before the survey than heterosexual men ( $79 \%$ vs. $62 \%$; adjusted $\mathrm{OR}[\mathrm{aOR}]=2.06 ; 95 \% \mathrm{CI}=1.28,2.99)$. Among those men who had heard of HPV, less than one third correctly responded that HPV can cause oral, anal, and penile cancers (Table 2). Gay and bisexual men were more likely than heterosexual men to correctly respond that $\mathrm{HPV}$ is not rare $(\mathrm{aOR}=1.81 ; 95 \% \mathrm{CI}=1.11$, 
2.94), that HPV causes health problems for males $(\mathrm{aOR}=1.89 ; 95 \% \mathrm{CI}=1.20,2.99)$, and that $\mathrm{HPV}$ can cause genital warts $(\mathrm{aOR}=2.09 ; 95 \% \mathrm{CI}=1.30,3.34)$.

Gay and bisexual men reported greater perceived knowledge about HPV-related diseases, perceived likelihood of developing HPV-related disease, and worry about HPV-related diseases than heterosexual men (all $p<.05$; Table 3). Gay and bisexual men also anticipated greater regret if they declined HPV vaccination and later developed HPV-related disease ( $p$ $<.001)$.

\section{HPV Vaccine}

More gay and bisexual men reported hearing about HPV vaccine than heterosexual men (73\% vs. $63 \%$ ) in bivariate analyses, but the groups did not differ in multivariate analyses (Table 4). Few men $(51 / 608,8 \%)$ reported knowing someone who had received HPV vaccine, most frequently daughters $(n=19)$, female friends $(n=17)$, or other family members $(n=14)$. Among men who had heard of HPV vaccine, more gay and bisexual men reported somewhat or mostly positive opinions of it than heterosexual men (70\% vs. $57 \%)$ in bivariate analyses, but the groups did not differ in multivariate analyses. Gay and bisexual men reported greater perceived effectiveness of HPV vaccine than heterosexual men $(p<$. 05). Sixty-six percent of heterosexual men and $60 \%$ of gay and bisexual men believed that HPV vaccine was only for women, whereas only $13 \%$ of heterosexual men and $18 \%$ of gay and bisexual men thought doctors were allowed to give HPV vaccine to males (differences not significant). Gay and bisexual men were more likely than heterosexual men to think HPV vaccine worked in males $(21 \%$ vs. $7 \%$; $\mathrm{aOR}=2.23 ; 95 \% \mathrm{CI}=1.04,4.78)$ and that their doctor would recommend HPV vaccine ( $34 \%$ vs. $16 \%$; $\mathrm{aOR}=2.47 ; 95 \% \mathrm{CI}=1.57$, 3.90).

Gay and bisexual men were more willing to receive HPV vaccine than heterosexual men ( $73 \%$ vs. $37 \%$; $\mathrm{aOR}=3.17 ; 95 \% \mathrm{CI}=2.14,4.70$ ). One heterosexual man and three gay and bisexual men reported unsuccessful attempts to get HPV vaccine for themselves. Reasons for not getting vaccinated included a health care provider who would not give the vaccine to males $(n=2)$ and being unable to afford the cost of the vaccine $(n=2)$.

\section{Discussion}

Most men had heard of HPV and HPV vaccine prior to our survey. Among many differences observed, an especially striking finding was that gay and bisexual men's self-reported willingness to receive HPV vaccine was twice that of heterosexual men. Gay and bisexual men also had higher knowledge and perceived knowledge about HPV-related diseases, perceived likelihood of developing HPV-related diseases, perceived effectiveness of HPV vaccine, belief that their doctor would recommend HPV vaccine, worry about HPV-related diseases, and anticipated regret if they declined HPV vaccine and later developed HPVrelated disease.

The high acceptability of HPV vaccine among gay and bisexual men was comparable with that found in previous studies of adult women and parents. A recent systematic review found that HPV vaccine acceptability ranged between 55\% and 100\% in these groups (Brewer \& Fazekas, 2007). Lower HPV vaccine acceptability among heterosexual men than among gay and bisexual men mirrors findings in previous studies of men, though it was unclear until now whether this finding was due to methodological differences among these studies. A survey of heterosexual men aged 18 to 45 years found that only $33 \%$ wanted to receive HPV vaccine (Ferris et al., 2008), but surveys of heterosexual male college students aged 18 to 24 years found moderate to high willingness to receive the vaccine (51\% to $76 \%$; Gerend \& 
Barley, 2009; Jones \& Cook, 2008). An Australian survey of men who have sex with men (MSM) found moderate willingness to receive the vaccine (47\%; Simatherai et al., 2009).

A handful of men had sought HPV vaccine for themselves and very few reported knowing a female who had received the vaccine, indicating that few survey participants had direct experience with HPV vaccine. However, gay and bisexual men may be more aware of sexual health topics than heterosexual men because of the disproportionate effect of the HIV epidemic on MSM as well as possible greater exposure to other sexual health messages that target MSM (e.g., syphilis awareness campaigns). This is one possible explanation for the greater perceived sexual risks and greater willingness to adopt preventive behaviors, including HPV vaccination that we observed among gay and bisexual men. Another potential contributing factor is the much larger proportion of heterosexual men than gay and bisexual men who reported being in a monogamous relationship with a single partner. These men may perceive themselves at low-risk for HPV and subsequently have little interest in receiving HPV vaccine.

Previous research among gay men has found low HPV knowledge (Pitts, Fox, Willis, \& Anderson, 2007) and frequent failure to recognize the connection between HPV infection and genital warts (Tider, Parsons, \& Bimbi, 2005). The majority of our sample was aware of HPV, but their knowledge of HPV-related diseases was low. Most men believed that HPV vaccine was only for women, and few thought that HPV vaccine works in males or that doctors can give HPV vaccine to males. These findings illustrate the challenges that medical and public health professionals may face should HPV vaccine become a public health priority for young men. The dramatic differences in acceptability by sexual orientation suggest a need for different educational interventions about HPV-related diseases and the vaccine for gay and bisexual men versus heterosexual men. For example, heterosexual men might benefit from education about HPV, the likelihood of getting HPV-related diseases, and the efficacy of HPV vaccine to increase acceptability because they reported lower levels of these variables than gay or bisexual men. Because a high proportion of gay and bisexual men already reported positive opinions of HPV vaccine and willingness to get vaccinated, a targeted intervention could address specific barriers to vaccine uptake.

Given that infection with HPV, including oncogenic Types 16 and 18 and nononcogenic Types 6 and 11, is widespread among sexually active men (Dunne, Nielson, Stone, Markowitz, \& Giuliano, 2006; Giuliano, Tortolero-Luna, et al., 2008), the current strategy of vaccinating only girls and young women for HPV is likely to be insufficient for widespread public health benefit. Even if we achieve high levels of HPV vaccination among young women, young MSM may not benefit from herd immunity conferred to heterosexuals. Although vaccinating young heterosexual men prior to sexual debut may potentially benefit their female partners, it is unlikely to be a sufficient motivation. Gerend and colleagues found that potential protection from HPV-related diseases for female partners did not increase heterosexual men's acceptability HPV vaccine (Gerend \& Barley, 2009). We have found, however, that gay and heterosexual men's interest in HPV vaccine doubled when it was described as preventing cancer that the men themselves might get (unpublished data).

Strengths of our study include a large, national sample and high participation rate. Limitations include the cross-sectional design and reliance on self-report. Our survey company composed its survey panel using random-digit dialing, thus excluding households without landline telephones. The company sought to minimize barriers to participation in their panels by providing Internet access for completing its Internet-based surveys. As much of our sample was middle aged, the generalizability of our findings to young men, for whom HPV vaccine was approved, will need to be further explored. We may have partially addressed this issue by controlling for age in our adjusted analyses. Future research will also 
need to confirm the generalizability of our findings to men of color and men with lower education levels, household incomes less than $\$ 60,000$, and rural residents. HIV infection was almost perfectly confounded with sexual orientation; only 1 of the 53 HIV-positive participants was heterosexual. To evaluate potential bias, we performed a sensitivity analysis in which we removed HIV-positive participants from the samples (data not shown). Study findings were largely unchanged.

These findings add to the growing literature on men's acceptability of HPV vaccine by providing data using comparably sized samples of gay or bisexual and heterosexual men from a national panel. We identified striking differences in HPV knowledge, perceptions of HPV-related diseases, and HPV vaccine acceptability by sexual orientation, which may inform interventions to increase men's uptake of HPV vaccine. Gay and bisexual men reported greater perceived knowledge of HPV and HPV-related diseases and many appeared ready to adopt HPV vaccine. Heterosexual men, however, may benefit from targeted education about HPV-related diseases and the direct risk to them to increase their interest in HPV vaccine.

\section{Acknowledgments}

Kim Chantala assisted in preparation of the data set for analysis.

Funding

The author(s) disclosed receipt of the following financial support for the research and/or authorship of this article:

A research grant to Noel T. Brewer, PhD, from the Investigator-Initiated Studies Program of Merck \& Co., Inc. funded the study.

\section{References}

Anonymous. Panel fails to push vaccine for males. The Washington Post. 2009 October 27.:1.

Backes DM, Kurman RJ, Pimenta JM, Smith JS. Systematic review of human papillomavirus prevalence in invasive penile cancer. Cancer Causes \& Control. 2009; 20:449-457. [PubMed: 19082746]

Baker, L.; Bundorf, M.; Singer, S.; Wagner, T. Validity of the survey of health and the internet and knowledge network's panel and sampling. Stanford, CA: Stanford University; 2003.

Brewer NT, Fazekas KI. Predictors of HPV vaccine acceptability: A theory-informed, systematic review. Preventive Medicine. 2007; 45:107-114. [PubMed: 17628649]

Brody J. HPV Vaccine: Few risks, many benefits. The New York Times. 2007 May 15. Retrieved from http://www.nytimes.com/2007/05/15/health/15brod.html.

Bush M. HPV vaccine for MSM. Australian Nursing Journal. 2008; 16(3):33.

Daling JR, Weiss NS, Hislop TG, Maden C, Coates RJ, Sherman KJ, Corey L. Sexual practices, sexually transmitted diseases, and the incidence of anal cancer. New England Journal of Medicine. 1987; 317:973-977. [PubMed: 2821396]

Dunne EF, Markowitz LE. Genital human papillomavirus infection. Clinical Infectious Diseases. 2006; 43:624-629. [PubMed: 16886157]

Dunne EF, Nielson CM, Stone KM, Markowitz LE, Giuliano AR. Prevalence of HPV infection among men: A systematic review of the literature. Journal of Infectious Diseases. 2006; 194:1044-1057. [PubMed: 16991079]

Fazekas KI, Brewer NT, Smith JS. HPV vaccine acceptability in a rural Southern area. Journal of Women's Health. 2008; 17:539-548.

Ferris DG, Waller JL, Miller J, Patel P, Jackson L, Price GA, Wilson C. Men's attitudes toward receiving the human papillomavirus vaccine. Journal of Lower Genital Tract Disease. 2008; 12:276-281. [PubMed: 18820541] 
Ferris DG, Waller JL, Miller J, Patel P, Price GA, Jackson L, Wilson C. Variables associated with human papillomavirus (HPV) vaccine acceptance by men. Journal of the American Board of Family Medicine. 2009; 22:34-42. [PubMed: 19124631]

Frisch M, Glimelius B, van den Brule AJ, Wohlfahrt J, Meijer CJ, Walboomers JM, Melbye M. Sexually transmitted infection as a cause of anal cancer. New England Journal of Medicine. 1997; 337:1350-1358. [PubMed: 9358129]

Gerend MA, Barley J. Human papillomavirus vaccine acceptability among young adult men. Sexually Transmitted Diseases. 2009; 36:58-62. [PubMed: 18830138]

Gillison ML. Human papillomavirus-related diseases: Oropharynx cancers and potential implications for adolescent HPV vaccination. Journal of Adolescent Health. 2008; 43 Suppl. 4:S52-S60. [PubMed: 18809146]

Gillison ML, Chaturvedi AK, Lowy DR. HPV prophylactic vaccines and the potential prevention of noncervical cancers in both men and women. Cancer. 2008; 113 Suppl. 10:3036-3046. [PubMed: 18980286]

Giuliano AR. Human papillomavirus vaccination in males. Gynecologic Oncology. 2007; 107 Suppl. 1(2):S24-S26. [PubMed: 17938015]

Giuliano AR, Lu B, Nielson CM, Flores R, Papenfuss MR, Lee JH, Harris RB. Age-specific prevalence, incidence, and duration of human papillomavirus infections in a cohort of 290 US men. Journal of Infectious Diseases. 2008; 198:827-835. [PubMed: 18657037]

Giuliano AR, Salmon D. The case for a gender-neutral (universal) human papillomavirus vaccination policy in the United States: Point. Cancer Epidemiology, Biomarkers, \& Prevention. 2008; 17:805-808.

Giuliano AR, Tortolero-Luna G, Ferrer E, Burchell AN, de Sanjose S, Kjaer SK, Bosch FX. Epidemiology of human papillomavirus infection in men, cancers other than cervical and benign conditions. Vaccine. 2008; 26 Suppl. 10:K17-K28. [PubMed: 18847554]

Holly EA, Whittemore AS, Aston DA, Ahn DK, Nickoloff BJ, Kristiansen JJ. Anal cancer incidence: Genital warts, anal fissure or fistula, hemorrhoids, and smoking. Journal of the National Cancer Institute. 1989; 81:1726-1731. [PubMed: 2810388]

Hoots BE, Palefsky JM, Pimenta JM, Smith JS. Human papillomavirus type distribution in anal cancer and anal intraepithelial lesions. International Journal of Cancer. 2009; 124:2375-2383.

Jones M, Cook R. Intent to receive an HPV vaccine among university men and women and implications for vaccine administration. Journal of the American College of Health. 2008; 57:2332.

Keating KM, Brewer NT, Gottlieb SL, Liddon N, Ludema C, Smith JS. Potential barriers to HPV vaccine provision among medical practices in an area with high rates of cervical cancer. Journal of Adolescent Health. 2008; 43 Suppl. 4:S61-S67. [PubMed: 18809147]

Liddon N, Hood J, Wynn BA, Markowitz LE. Acceptability of human papillomavirus vaccine for males: A review of the literature. Journal of Adolescent Health. 2010; 46:113-123. [PubMed: 20113917]

Markowitz, L. Update and new recommendations: Human papillomavirus Vaccines. NetConference, Centers for Disease Control and Prevention; 2009 November 12. Retrieved from http://www.cdc.gov/vaccines/ed/ciinc/downloads/Nov_09/NICRDnetconf2009final.ppt

Markowitz LE, Dunne EF, Saraiya M, Lawson HW, Chesson H, Unger ER. Quadrivalent human papillomavirus vaccine: Recommendations of the Advisory Committee on Immunization Practices (ACIP). Morbidity and Mortality Weekly Report, Recommendations and Reports. 2007; 56(RR-2):1-24. [PubMed: 17380109]

Molloy F. Timetable to beat a virus. Sydney Morning Herald (Australia). 2008 March 6. Retrieved from http://www.smh.com.au/news/health/timetable-to-beat-a-virus/ 2008/03/06/1204779952297.html.

Palefsky J. Human papillomavirus and anal neoplasia. Current HIV/AIDS Reports. 2008; 5:78-85. [PubMed: 18510893]

Picard A. Should HPV vaccinations be extended to young men? The Globe and Mail (Canada). 2007 March 27.:A21. 
Pitts MK, Fox C, Willis J, Anderson J. What do gay men know about human papillomavirus? Australian gay men's knowledge and experience of anal cancer screening and human papillomavirus. Sexually Transmitted Diseases. 2007; 34:170-173. [PubMed: 16837830]

Reiter PL, Brewer NT, McRee AL, Gilbert P, Smith JS. Acceptability of HPV vaccine among a national sample of gay and bisexual men. Sexually Transmitted Diseases. 2010; 37:197-203. [PubMed: 20118831]

Reiter PL, Brewer NT, Smith JS. HPV knowledge and HPV vaccine acceptability among a national sample of heterosexual males. Sexually Transmitted Infections. 2009 doi:10.1136/sti.2009.039065.

Simatherai D, Catriona CS, Fairley CK, Bush M, Heley S, Chen MY. What men who have sex with men think about the human papillomavirus vaccine. Sexually Transmitted Infections. 2009 doi: 10.1136/sti.2008.032581.

Singer N. Vaccine against virus in girls may be given to boys. The New York Times. 2009:1.

Tider DS, Parsons JT, Bimbi DS. Knowledge of human papillomavirus and effects on sexual behaviour of gay/bisexual men: a brief report. International Journal of STD \& AIDS. 2005; 16:707-708. [PubMed: 16212721]

Walboomers JM, Jacobs MV, Manos MM, Bosch FX, Kummer JA, Shah KV, Muñoz N. Human papillomavirus is a necessary cause of invasive cervical cancer worldwide. Journal of Pathology. 1999; 189:12-19. [PubMed: 10451482]

Willis, GB. Cognitive interviewing: A tool for improving questionnaire design. Thousand Oaks CA: Sage; 2005. 


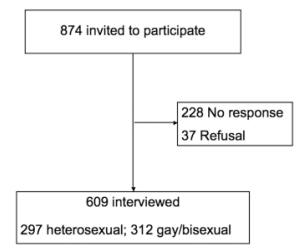

Figure 1.

Flow diagram 
Table 1

Demographic Characteristics of Participants

\begin{tabular}{|c|c|c|c|}
\hline & Heterosexual, $n(\%)$ & Gay/Bisexual, $n(\%)$ & $p$ \\
\hline \multicolumn{4}{|l|}{ Age (years) } \\
\hline $19-39$ & $109(37)$ & $60(19)$ & $<.001$ \\
\hline $40-49$ & $90(30)$ & $127(41)$ & \\
\hline $50-59$ & $97(33)$ & $125(40)$ & \\
\hline \multicolumn{4}{|l|}{ Race/ethnicity } \\
\hline White, non-Hispanic & $230(78)$ & $253(81)$ & .302 \\
\hline Other race/ethnicity & $66(22)$ & $59(19)$ & \\
\hline \multicolumn{4}{|l|}{ Educational attainment } \\
\hline No college degree & $197(67)$ & $138(44)$ & \\
\hline Bachelor degree or higher & $99(33)$ & $174(56)$ & $<.001$ \\
\hline \multicolumn{4}{|l|}{ Annual household income } \\
\hline$<\$ 60,000$ & $147(50)$ & $126(40)$ & .022 \\
\hline$\geq \$ 60,000$ & $149(50)$ & $186(60)$ & \\
\hline \multicolumn{4}{|l|}{ Age at first intercourse ${ }^{a}$} \\
\hline$<16$ years & $71(25)$ & $109(33)$ & .005 \\
\hline$\geq 16$ years & $213(75)$ & $196(64)$ & \\
\hline \multicolumn{4}{|l|}{ Lifetime sex partners $^{a}$} \\
\hline$\leq 4$ partners & $111(39)$ & $31(10)$ & $<.001$ \\
\hline 5-19 partners & $115(41)$ & $70(23)$ & \\
\hline 20-49 partners & $40(14)$ & $82(27)$ & \\
\hline$\geq 50$ partners & $18(6)$ & $122(40)$ & \\
\hline \multicolumn{4}{|l|}{ Ever had STI } \\
\hline No & $263(89)$ & $215(69)$ & $<.001$ \\
\hline Yes & $33(11)$ & $97(31)$ & \\
\hline \multicolumn{4}{|l|}{ Sexual risk in past year $b$} \\
\hline No sexual partners & $45(16)$ & $54(18)$ & $<.001$ \\
\hline One mutually monogamous regular partner & $181(65)$ & $71(24)$ & \\
\hline Two or more partners or a nonmonogamous regular partner & $51(18)$ & $175(58)$ & \\
\hline HIV positive & $1(<1)$ & $52(17)$ & $<.001$ \\
\hline Current smoker & $75(26)$ & $89(29)$ & .376 \\
\hline \multicolumn{4}{|l|}{ Health insurance status } \\
\hline Yes & $244(82)$ & $267(86)$ & .290 \\
\hline No & $52(18)$ & $45(14)$ & \\
\hline \multicolumn{4}{|l|}{ Employment status } \\
\hline Not currently employed & $58(20)$ & $60(19)$ & .910 \\
\hline Currently employed & $238(80)$ & $252(81)$ & \\
\hline \multicolumn{4}{|l|}{ Urbanicity } \\
\hline Urban & $242(82)$ & $292(94)$ & $<.001$ \\
\hline Rural & $54(18)$ & $20(6)$ & \\
\hline
\end{tabular}




\begin{tabular}{lrrr}
\hline & Heterosexual, $\boldsymbol{n}(\boldsymbol{\%})$ & Gay/Bisexual, $\boldsymbol{n}(\boldsymbol{\%})$ & $\boldsymbol{p}$ \\
\hline Region of residence & & & \\
Northeast & $52(17)$ & $48(15)$ & .575 \\
Midwest & $64(22)$ & $72(23)$ & \\
South & $113(38)$ & $109(35)$ & \\
West & $67(23)$ & $83(37)$ \\
\hline
\end{tabular}

Note. STI $=$ sexually transmitted infection, including genital warts; HPV $=$ human papillomavirus. Heterosexual $(n=296)$ versus gay/bisexual men $(n=312)$.

${ }^{a}$ Excludes 12 heterosexual men and 7 gay/bisexual men who reported never having vaginal, oral, or anal sex.

$b_{\text {Excludes }} 11$ heterosexual men and 12 gay/bisexual men because of item nonresponse. 
Table 2

HPV Knowledge

\begin{tabular}{lrrrr}
\hline & $\begin{array}{r}\text { Heterosexual, } \\
\boldsymbol{n}(\boldsymbol{\%})\end{array}$ & $\begin{array}{r}\text { Gay/Bisexual, } \\
\boldsymbol{n}(\boldsymbol{\%})\end{array}$ & $\begin{array}{l}\text { Bivariate OR } \\
\mathbf{( 9 5 \%} \mathbf{C I})\end{array}$ & $\begin{array}{l}\text { Adjusted OR } \\
\mathbf{( 9 5 \%} \mathbf{C I})\end{array}$ \\
\hline HPV can cause genital warts & $62(34)$ & $114(46)$ & $1.66(1.12,2.46)^{*}$ & $2.09(1.30,3.34)^{*}$ \\
HPV can cause oral cancer & $38(21)$ & $62(25)$ & $1.27(0.80,2.01)$ & $1.26(0.74,2.15)$ \\
HPV can cause anal cancer & $26(14)$ & $79(32)$ & $2.84(1.73,4.65)^{* *}$ & $2.90(1.64,5.13)^{* *}$ \\
HPV can cause penile cancer & $31(17)$ & $68(28)$ & $1.85(1.15,2.98)^{*}$ & $2.37(1.35,4.14)^{*}$ \\
HPV causes health problems for males & $81(45)$ & $144(58)$ & $1.74(1.18,2.57)^{*}$ & $1.89(1.20,2.99)^{*}$ \\
You can get HPV from having sex & $121(67)$ & $184(75)$ & $1.47(0.97,2.24)$ & $1.39(0.84,2.30)$ \\
HPV can cause genital herpes & $58(32)$ & $82(33)$ & $1.06(0.71,1.60)$ & $1.07(0.66,1.74)$ \\
HPV infection is rare & $110(61)$ & $184(75)$ & $1.91(1.27,2.89)^{*}$ & $1.81(1.11,2.94)^{*}$ \\
Only people who have sex with lots of other people get HPV & $106(58)$ & $166(67)$ & $1.47(0.99,2.19)$ & $1.46(0.91,2.32)$ \\
\hline
\end{tabular}

Note . OR = odds ratio; $95 \% \mathrm{CI}=95 \%$ confidence interval; $\mathrm{HPV}=$ human papillomavirus; $\mathrm{STI}=$ sexually transmitted infection. Adjusted analyses control for age, educational attainment, household income, previous STI diagnosis, number of lifetime sex partners, and urbanicity. Gay/bisexual ( $n$ = 247) versus heterosexual ( $\mathrm{n}=182)$ men who had heard of HPV prior to the survey. Correct response is "yes" for all but last three items.

$p<.05$.

**

$p<.001$. 
Table 3

Perceptions of HPV, HPV-Related Diseases, and HPV Vaccine

\begin{tabular}{lllll}
\hline & $\begin{array}{l}\text { Heterosexual, } \\
\boldsymbol{M}(\boldsymbol{S D})\end{array}$ & $\begin{array}{l}\text { Gay/Bisexual, } \\
\boldsymbol{M}(\boldsymbol{S D})\end{array}$ & $\begin{array}{l}\text { Unadjusted } \boldsymbol{\beta} \\
\text { Adjusted } \boldsymbol{\beta}\end{array}$ \\
\hline Perceived knowledge about HPV-related diseases $^{a}$ & $1.51(0.48)$ & $1.80(0.63)$ & $.25^{* *}$ & $.19^{* *}$ \\
Perceived severity of HPV-related diseases $^{a}$ & $3.24(0.73)$ & $3.33(0.65)$ & .06 & .05 \\
Perceived likelihood of getting HPV-related disease $^{b}$ & $1.89(0.63)$ & $2.19(0.55)$ & $.25^{* *}$ & $.23^{* *}$ \\
Perceived effectiveness of HPV vaccine $^{c}$ & $2.65(0.87)$ & $3.03(0.82)$ & $.22^{* *}$ & $.12^{*}$ \\
Perceived barriers to getting HPV vaccine $^{d}$ & $2.76(0.87)$ & $2.67(0.85)$ & -.05 & .04 \\
Worry about HPV-related diseases $^{a}$ & $1.30(0.44)$ & $1.54(0.54)$ & $.24^{* *}$ & $.15^{*}$ \\
$\begin{array}{l}\text { Anticipated regret if declined HPV vaccine and develops HPV-related } \\
\text { disease }\end{array}$ & $2.93(1.05)$ & $3.39(0.83)$ & $.24^{* *}$ & $.18^{* *}$ \\
Greatest amount willing to pay out-of-pocket for HPV vaccine $^{a *}$ & $\$ 110(268.6)$ & $\$ 131(138.3)$ & .05 & .06 \\
\hline
\end{tabular}

Note. $\mathrm{HPV}=$ human papillomavirus. Adjusted analyses control for age, educational attainment, household income, previous STI diagnosis, number of lifetime sex partners, and urbanicity. $\beta=$ standardized linear regression coefficient. Gay/bisexual $(n=312)$ versus heterosexual $(n=296)$ men.

${ }^{a} 4$-Point response scale, $1=$ nothing at all or not at all to $4=$ quite $a$ lot.

$b_{5-P o i n t}$ response scale, $1=$ no chance to $5=$ certain $I$ will get [disease] .

${ }^{c}$-Point response scale, $1=$ no protection to $5=$ complete protection .

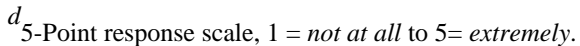

* $p<.05$.

** $p<.001$. 
Table 4

HPV Vaccine Awareness, Beliefs, and Attitudes

\begin{tabular}{|c|c|c|c|c|}
\hline & $\begin{array}{r}\text { Heterosexual, } \\
n(\%)\end{array}$ & $\begin{array}{r}\text { Gay/Bisexual, } \\
n(\%)\end{array}$ & $\begin{array}{l}\text { Unadjusted OR } \\
(95 \% \text { CI })\end{array}$ & $\begin{array}{l}\text { Adjusted OR } \\
(95 \% \text { CI })\end{array}$ \\
\hline Heard of HPV before survey & $182(62)$ & $247(79)$ & $2.42(1.69,3.47)^{* *}$ & $2.06(1.28,2.99)^{*}$ \\
\hline Heard of HPV vaccine before survey & $186(63)$ & $228(73)$ & $1.63(1.15,2.29)^{*}$ & $1.47(0.98,2.21)$ \\
\hline Willing to receive HPV vaccine & $109(37)$ & $229(73)$ & $4.73(3.35,6.68)^{* *}$ & $3.17(2.14,4.70)^{* *}$ \\
\hline Believes doctor would recommend HPV vaccine & $47(16)$ & $105(34)$ & $2.69(1.82,3.97)^{* *}$ & $2.47(1.57,3.90)^{* *}$ \\
\hline Somewhat or mostly positive opinion of HPV vaccine $a$ & $105(57)$ & $160(70)$ & $1.81(1.21,2.72)^{*}$ & $1.34(0.83,2.18)$ \\
\hline Thinks HPV vaccine is only for women ${ }^{a}$ & $122(66)$ & $134(60)$ & $0.77(0.52,1.16)$ & $0.82(0.51,1.33)$ \\
\hline Thinks HPV vaccine works in males ${ }^{a}$ & $13(7)$ & $47(21)$ & $3.46(1.80,6.61)^{* *}$ & $2.23(1.04,4.78)^{*}$ \\
\hline Thinks doctors are allowed to give HPV vaccine to males ${ }^{a}$ & $24(13)$ & $42(18)$ & $1.52(0.89,2.63)$ & $1.43(0.75,2.75)$ \\
\hline
\end{tabular}

Note. $\mathrm{OR}=$ odds ratio. $95 \% \mathrm{CI}=95 \%$ confidence interval. HPV $=$ human papillomavirus. Adjusted analyses control for age, educational attainment, household income, previous STI diagnosis, number of lifetime sex partners, and urbanicity. Gay/bisexual $(n=312)$ versus heterosexual $(n=296)$ men.

${ }^{a}$ Assessed only of heterosexual men $(n=186)$ and gay/bisexual men $(n=228)$ who reported hearing about HPV vaccine prior to survey. $*$ p $<.05$.

$* *$ $p<.001$. 